\title{
Effect on Textile Behavior of Fleece Types and Dehairing Process on the Linear Density and Regularity of Yarn from Argentine Llama Fibre
}

\author{
Frank EN ${ }^{1,2 *}$, Hick MVH ${ }^{1,2}$, Castillo MF $^{1}$ and Seghetti Frondizi DG $^{3}$ \\ ${ }^{1}$ IRNASUS-CONICET-UCC, Argentina \\ ${ }^{2}$ Sede Chamical UNLAR, Argentina \\ ${ }^{3}$ Textile private entrepreneur, Argentina
}

*Corresponding author: Eduardo Frank, Designation Professor, Catholic University of Cordoba, UNLAR, 3555 Cordoba - Argentina.

Received Date: March 07, 2019

Published Date: March 13, 2019

\section{Introduction}

The textile industry usually ignores the existence of types of fleece in South American Camelids, however its biological base has been widely demonstrated [1]. On the other hand, it is suggested the utility of classifying the lots by types of fleeces, before dehairing, foreseeing a differential textile behavior of the fiber $[2,3]$.

Comparing the textile behavior of various Australian wool, cashmere and alpaca, it has been shown that the regularity and general quality of the yarn depend to a large extent on the type of crude fiber of which it is composed [4].

In a very extensive work on fabric softness, all judges perceive alpaca fiber $(26 \mu \mathrm{m})$ to be significantly softer than wool of the same diameter, also the softness of alpaca fibre could not be distinguished from the softness to the fine Merino wool $(17 \mu \mathrm{m})$. This first evaluation was about wool and alpaca tops. But, on the other hand, most of the same judges found the surface of the alpaca fabrics more prickly than wool yarn of similar fineness, because the alpaca fabrics was more hairiness than the wool fabrics of similar yarn fiber diameter, and this surface effect of hairiness interfere on softness and prickling perception of consumers [4]. It is necessary to emphasize that the alpaca fibre was not dehaired in this work.

The lack of evenness of a yarn may be due to an irregular number of fibers per yarn cross section or to irregularity of fiber diameter [5].

Since the dehairing process alters the composition of fiber types of the structure of the original fleece [2], it is hypothesized that an important effect of dehairing on the regularity of the yarn occurs.

The objective of this work is to demonstrate the differential behavior of the types of fleece under dehairing process on yarn linear density and on the yarn regularity.

\section{Materials and Methods}

Eighteen (18) fleeces belonging to the following types of fleece (FT) [2,3]: Double coated (DC, 3): Intermediate coated (IC 4); Simple coated (SC, 4), Hemilustre (HL, 3) and Luster (L, 4), have been used (Figures 1 \& 2). The average diameter of total fiber (DMFT) and the coefficient of variation of diameter are presented in Table 1.

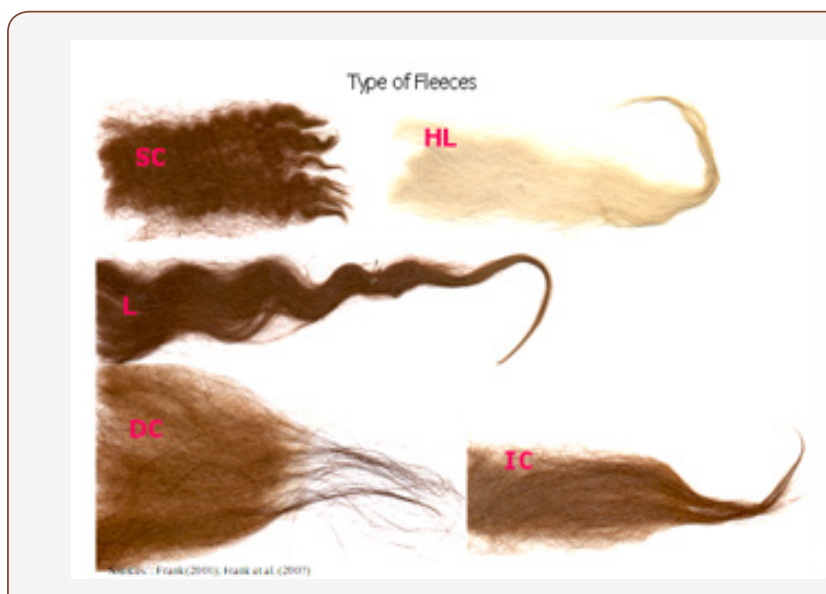

Figure 1: Diagrammatic representation of type of fleece of Argentine Llamas. 


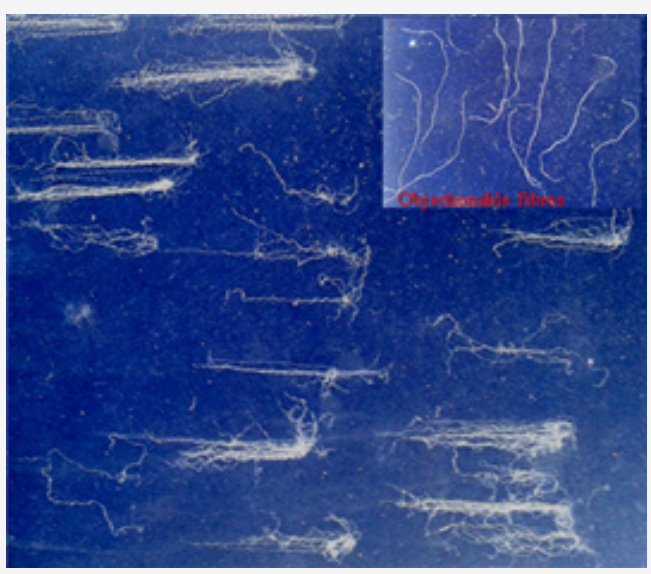

Figure 2: Velvet coat with dissected South American Camelids fibre and objectionable fibre in the right corner.

Table 1: Characteristics of the raw fibre samples by type of fleeces.

\begin{tabular}{|c|c|c|}
\hline Type of Fleeces & FD & FDcv \\
\hline Doble coated (DC) & 21.7 & 35.6 \\
\hline Intermediate coated (CI) & 20.5 & 35.6 \\
\hline Single coated (SC) & 23.3 & 27.1 \\
\hline Hemilustre (HL) & 24.1 & 27.7 \\
\hline Lustre (L) & 22.5 & 27.4 \\
\hline
\end{tabular}

Half of each fleece is subjected to a process ( $\mathrm{Tr}$ ) of laboratory dehairing (Des) and the other half was not dehaired (Ndes). They were spun with a laboratory spinning machine according to the woolen method [6]. A ring spinning process was emulated by controlling torsion and regularity manually, with equal speed and torsion factor for all yarns. In each count, 3 sections were cut, which in turn were subdivided into 2 extremes and 1 middle point. In cross sections, the fibers were counted under a magnifying glass (12x). The linear density (title) of each yarn section was calculated by the international system (Tex) and the length of each yarn section was weighed and measured to estimate the mass variation coefficient (CVH\%) throughout the yarn axis. The $\mathrm{CH} \%$ was assumed as an approximation to the squared coefficient of variation of Uster [7].

From Martindale's theoretical equation, the potential title of each section was calculated using FD and FDCV, the constant (972 and $\mathrm{CVH} \%$ ) and the number of real fibers counted per section (Nn) [6], resulting in Texest and CVH\% est.

$$
\begin{aligned}
\mathrm{Nn}=\frac{((972 x(T e x))}{F D^{2} x\left(1+\left(\frac{F D_{C V}}{100}\right)^{2}\right)} & \Rightarrow \text { Texest }=\frac{\frac{972}{F D^{2} x\left(1+\left(\frac{F D_{C V}}{100}\right)^{2}\right)}}{N n} \\
& \Rightarrow \mathrm{CVH} \% \mathrm{est}=\frac{((972 x(T e x))}{F D^{2} x(\sqrt{N n})} \times 100
\end{aligned}
$$

The data of the measured and estimated variables were evaluated by comparison by Student $\mathrm{T}$ of paired means. ANOVA was performed for Tex and CVH\% considering FT, Tr, FTxTr as fixed variables. A mean comparison method based on Bautista clusters (BSS) [8] was used.

\section{Results and Discussion}

Yarn evenness, defined as the variation of mass per unit length, can affect several properties of textile materials, especially, the final appearance of the woven/knitted fabric. This problem is particularly important when it appears at regular intervals along the yarn length, causing imperfections in the final product [9]. For its detection, this work was made considering the dehairing process can alter the structure of the fleece regarding presence and/or frequency of objectionable types of fibers [3].

Some of the most important parameters used in the specification of yarn quality are linear density (linear mass or title), structural characteristics and composition of fibers. This was the reason why the measured linear density (Tex) and the linear density estimated (Texest) from Martindale equation were used to verify the correct determination of the parameters that compose it.

The paired comparison between Tex and Texest gave significant $(p<0.0001)$ in Des and non-significant ( $p>0.4709$ ) in NDes, while CVH\% vs CVH\% was significant in Ndes and not significant in Des, indicating a behavior contrary to linear density behavior. On FT, Tex vs. Texest was significant while $\mathrm{CVH} \%$ gave significant into $\mathrm{DC}, \mathrm{CI}$ and HL, while SC and $\mathrm{L}$ did not give significant ( $\mathrm{p}>0.05)$. This is in agreement with that found in Frank EN, et al. [3] which shows that the yarn of types SC and L are more evenness than with the other types of fleece. The FDcv of the fiber seems to be a good estimator of the CVH\% of the yarn, according to the theory developed [7].

The Martindale equation only estimates linear density limits obtainable with a number of fibers in the section of the yarn [6], that seems unclear in the difference of title and regularity when comparing Des with Ndes. Here we also used the Nn that was actually counted in each section, and this variable (Nn) served to obtain a better adjust of the equation and achieved a lower variation in its estimate.

Table 2: Comparison of linear density (Tex) among type of fleeces, under dehairing and non-dehairing process.

\begin{tabular}{|c|c|c|}
\hline Type of Fleeces & Dehaired & Non dehaired \\
\hline Doble coated (DC) & $18.43 \mathrm{~b}$ & $20.13 \mathrm{~b}$ \\
\hline Intermediate coated (IC) & $24.72 \mathrm{~d}$ & $25.3 \mathrm{~d}$ \\
\hline Single coated (SC) & $20.19 \mathrm{~b}$ & $22.28 \mathrm{c}$ \\
\hline Hemilustre (HL) & $13.94 \mathrm{a}$ & $25.76 \mathrm{~d}$ \\
\hline Lustre (L) & $18.24 \mathrm{~b}$ & $28.17 \mathrm{e}$ \\
\hline
\end{tabular}

Table 3: Comparison of regularity (CVH\%) among type of fleeces, under dehairing and non-dehairing process.

\begin{tabular}{|c|c|c|}
\hline Type of Fleeces & Dehaired & Non dehared \\
\hline Doble coated (DC) & $30.73 \mathrm{~b}$ & $26.53 \mathrm{~b}$ \\
\hline Intermediate coated (IC) & $18.19 \mathrm{a}$ & $21.93 \mathrm{a}$ \\
\hline Single coated (SC) & $32.69 \mathrm{~b}$ & $36.62 \mathrm{c}$ \\
\hline Hemilustre (HL) & $29.66 \mathrm{~b}$ & $36.82 \mathrm{~d}$ \\
\hline Lustre (L) & $30.66 \mathrm{~b}$ & $25.16 \mathrm{~b}$ \\
\hline
\end{tabular}

The ANOVA for Tex show significantly $(\mathrm{p}<0.001)$ for FT and Tr and for FT $\mathrm{x}$ Tr effects, while for CVH\% it was only significant in: FT 
$(\mathrm{p}<0.001), \operatorname{Tr}(\mathrm{p}>0.05))$ and FT $\mathrm{x} \operatorname{Tr}(\mathrm{p}<0.01)$. In Tables $2 \& 3$ the FT $x$ Tr interactions are compared by rows and along columns.

In Tex both DC and CI types behave the same in Des as in Ndes, but SC, HL and L, have significantly thicker yarns in Ndes than in Desc. In CVH\% the behavior is similar to Tex, but $\mathrm{L}$ does not have significant differences in regularity between Des and NDes, although it gave significantly thicker title in NDes. This significant finding could explain the discrepancy observed when testing alpaca tops and alpaca fabric with experts, in relation to the softness to the touch [4]. The softness of the fiber does not move completely to the yarn and/or fabric, if the regularity of the yarn is not achieved according to the actual diameter of the fiber. The same would be explained by the linear density of a yarn, which would be considerably improved by the dehairing process within all types, except for DC type of fleece.
The fineness of the yarn achieved in general in this assay was striking, if compared to another work where a $27 \mu \mathrm{m}$ wool yarn and $26 \mu \mathrm{m}$ alpaca yarn resulted as much as 33 tex and with a smaller number of fibers (45) [4]. The number of fibers per section does not seem to fully determine the linear density, although it is an important component in the uniformity [7].

The appearance of the surface of the fabric, dehaired and undehaired, can be clearly seen in Figure 3. The sensation of presenting less softness and greater prickling effect is enhanced by the visual observation of the objectionable fibers on the surface of the non-dehaired fabrics. This may explain the results of the panelists' tests that hurt the alpaca fabric in terms of its softness, although in its top form they had particularly appreciated its softness [4].

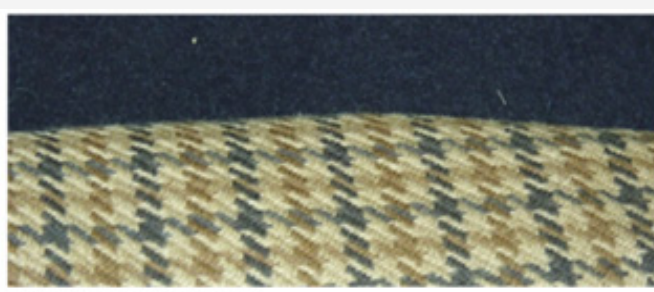

Dehaired fibre fabric

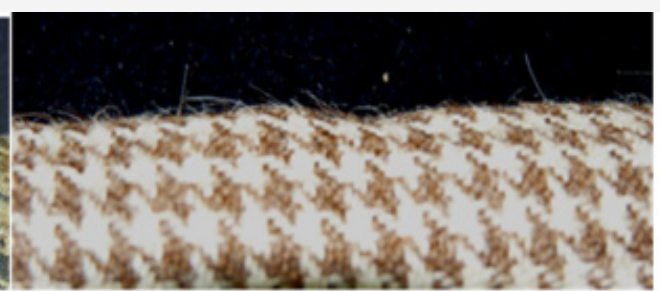

Non dehaired fibre fabric

Figure 3: Samples of fabric of South American Camelids fibre, under dehairing process and without dehairing.

\section{Conclusion}

The types of fleece behave differently to the dehairing, as much in lineal density (title) as in regularity. Therefore, it is important to consider their existence as different types and separate them by classification before being processed Argentine llama fiber.

This shows that it is absolutely indispensable, both the classification by types of fleece, as the dehairing process of each one of them in Argentine llama fiber.

\section{Acknowledgement}

Appreciation to the Ministry of Science and Technology of the province of Córdoba, Argentina. To the secretariat of Science, Technology and Technological Linkage of the Catholic University of Cordoba. Both institutions made contributions to finance this work.

\section{Conflict of Interest}

No conflict of interest.

\section{References}

1. Carvalho V, Monteiro JL, Soares FO, Vasconcelos RM (2008) Yarn evenness parameters evaluation: A new approach. Textile Research Journal 78(2): 119-127.
2. Rae A, Bruce R (1973) The WIRA textile data book, Leeds, UK.

3. Kim J, Jasper WJ, Suh MW, Woo JL (2000) Effect of Measurement Principle and Measuring Field on Uniformity Measures of Spun Yarns. Textile Research Journal 70(7): 584-587.

4. Di Rienzo JA, Guzmán AW, Casanovas F (2002) A Multiple Comparisons Method based on the Distribution of the Root Node Distance of a Binary Tree. Journal of Agricultural, Biological, and Environmental Statistics 7(2): 847-860.

5. Brodtmann LI, Hick MH, Castillo MF, Frank EN (2018) Conceptual description of the llama fleece structure and the potential of classing and dehairing. Textile Research Journal 88(12): 1384 - 1401.

6. Frank EN, Li B, de Neyra LA, Hubert Hick MV (2017) Análisis multivariado de los tipos de vellón en Llamas argentinas. RAPA 37(1): 278.

7. Frank EN, Hick MV, Adot O (2007) Descriptive differential attributes of type of fleeces in Llama fiber and its textile consequence. 1-Descriptive aspects. The Journal of The Textile Institute 98(3): 251-259.

8. Hillbrick, Karen L (2012) Fiber Properties affecting the Softness of Wool and other Keratins. Ph.D. Thesis, Deakin University, Australia.

9. Hasler A, Honegger E (1954) Yarn Evenness and its Determination. Textile Research Journal 24(1):73-85. 